| Forum |

\title{
Open access, scholarship, and digital anthropology
}

\author{
Daniel MiLler, University College London
}

This article consists of three arguments. The first advocates the development of Open Access for anthropological books and journals and critiques the way we have ceded control of dissemination to inappropriate commercial concerns that come to stand for what should have been academic criteria. The second argues that this is best accomplished while being conservative about the process of review, selection, and the canons of scholarship. Third, the article address the emergence of Digital Anthropology, suggesting this has considerable significance for the very conceptualization of anthropology and its future, and suggesting that it can be given definition. But, this should not be confused with the issues of Open Access and review. This is followed by ten helpful and critical comments. In the concluding discussion I respond to these and argue how these points can be taken into account in creating the conditions for a shift to Open Access while defending the concept of Digital Anthropology.

Keywords: Open Access, Digital Anthropology, peer review, scholarly publishing

The problem that this comment is intending to resolve is that we can easily conflate what are better seen as three distinct issues, though clearly each has implications for the other. The first is the advocacy for Open Access for anthropological writing and, in particular, an admission that we have ceded control to inappropriate commercial concerns that are a betrayal of the claims we constantly make about our own academic criteria. Second, I will argue that Open Access does not imply in and of itself anything about the way anthropologists take responsibility for critiquing and judging each other's work. As we move to Open Access dissemination, we should simultaneously be cautious about any other changes that weaken our claims to scholarship and the wider respect and authority for what anthropologists do. Third, just as scholarship needs to be considered in its own right apart from the issue of Open Access so does the emerging field of Digital Anthropology. I would strongly argue the latter is no gimmick. The impacts of digital technologies are likely to be among the most significant changes that we

(c) This work is licensed under the Creative Commons | (c) Daniel Miller. Attribution-NonCommercial-NoDerivs 3.0 Unported. ISSN 2049-1115 (Online) 
will encounter as ethnographic fieldworkers over the next generation. ${ }^{1}$ I will discuss each of these three points in turn.

Welcome though it is, $H A U$ is not the first Open Access online journal in anthropology. Indeed Alex Golub has noted that The Journal of Political Ecology started in 1994. One of these precedents is a journal called Anthropology Matters, which began publishing in 1999 and has concentrated on contributions from UK PhD students. In 2005 I published a paper in that journal called "Can't publish and be damned" (Miller 2005), which was a polemic against what I considered then-and consider now-to be an outrageous situation within the discipline: the degree to which what are supposed to be entirely academic criteria have been ceded to commercial considerations.

For PhD students hoping for a career in anthropology the main criterion by which they will be judged is their publications. Given the competition, this increasingly includes the expectation of having published a book, often a monograph. This is most commonly a rewritten extension of their $\mathrm{PhD}$ research. In turn, the department they join will also be judged by a now very well established government audit (at least in the UK). Their primary criterion includes judgment on four publications by each staff member, which represent their best work during the audit period. Now whatever one thinks of the recruitment of lecturers or auditing departments, the premise of both is that these publications are a direct outcome of purely academic adjudication. The best scholarship gets published at the expense of the lesser works.

There was a time when anthropology publishing in the United Kingdom was dominated by university presses who prided themselves on their academic reputations above all and would willingly (and thanks to subsidies) publish major tomes that were thoroughly uncommercial but milestones in academic scholarship. Those days are gone and today almost all presses are in essence commercial institutions. I spend a good deal of time advising students on writing book proposals and I have to inform them that the page about how many copies will be sold and why anyone would pay for them is now just as important as the academic argument. An excellent scholarly book on a particularly obscure or esoteric subject will mainly attract a flurry of rejections.

What this means is that by default, what still purports to be an academic criterion, has slipped into a largely commercial decision making process. Yet we proceed to evaluate students and departments without, as far as I can tell, anyone admitting to this discrepancy. A student can fail to get a job because his or her work is not commercial enough, even though his or her scholarship is outstanding. This was the disgraceful situation that was subject of my polemic in 2005. I did not, however, just want to castigate the discipline. I proposed a solution. At the time I had met up with a small print-on-demand press headed by an ex-PhD student in anthropology called Sean Kingston, who could afford to take on books with much lower sales figures and indeed often at a lower cost than many of the regular presses. I asked a number of the UK "great and the good" anthropologists such as Mary Douglas and Marilyn Strathern if they would serve on the editorial board, and they agreed. The point I wanted to make was that a book that went through

1 As Horst and I have argued elsewhere (Miller and Horst 2012), these impacts represent specific challenges and create a new significance for the discipline of anthropology itself. 
the same channels of adjudication, but simply was not commercially viable, could be published within our series and this would ensure that the career of the author and the access to this material was not limited by merely commercial considerations. Since the series began we have published books such as The potters and pottery of Miravet (van Veggel 2009) and The shark warrior of Alewai: A phenomenology of Melanesian identity (Van Heekeren 2012). This series continues and I would be happy to receive further submissions in the future. Although I am about to turn to the question of online Open Access material, I think there is still a niche for paper books and therefore for a series of this kind.

Nevertheless, the situation has changed since 2005 and the main emphasis today is on the possibility of Open Access online publication-including e-booksas an alternative means for bypassing commercial publishers. Current debates, which are evident in discussions at the AAA and in the blog Savage Minds (Thompson 2012), are just as much focused on the outrageous amounts that the academic world currently pay to publishers, especially the publishers of certain journals in science. The New York Times (Lin 2012) recently noted a specific boycott of Elsevier, a company that in 2010 increased profits by 36 percent to $\$ 3.2$ billion. I work very closely with publishers and do not wish to impugn the benefits to academics represented by good publishing companies who often suffer from the total lack of knowledge and comprehension about what they do on behalf of academic authors. But while there may be a baby, it is becoming evident that there is a lot of dirty and ridiculously overpriced bathwater we could do without. The Elsevier profits look rather like a self-inflicted tax on learning. In any case, the point I have just made would still stand. Commercial considerations should not vicariously stand in the stead of what purport to be academic criteria. So there seems an overwhelming case to support and promote Open Access publishing. In addition, I simply see no reason why we would want to prevent people from reading our work.

Anthropology has made a good contribution to this debate partly because in the work of Gabriella Coleman (2004, 2009, 2010), Jelena Karanović (2008, 2012), and many others there has been a genuine intellectual effort to conduct ethnographic work with the advocates of open source and free software partly as a way of understanding and promoting the ethos that such activists embody. This includes the rise of instruments such as Linux, Unix, and distributed free software such as Napster and Firefox. There are many reasons why these developments have been celebrated. They seem to betoken an escape from the endless increase in commoditization, and in certain areas, such as music, have led on to a quite effective de-commodification. Software that was shared and not sold seemed to realize the new efficiencies and relative costlessness of digital creation and communication. Some anthropologists are clearly sympathetic to wider political aim such as the freedom from control and governance represented by hacker groups and the activist interventions in politics associated with groups such as Anonymous studied by Coleman. With respect to the issue of publishing, however, I would suggest that the single most inspiring contribution has been that of Chris Kelty (2008) in his book Two Bits. After a monograph length treatment of the development of open source and a helpful theorization of what he termed the recursive public, the end of the book turns precisely to this issue of how we need not just to study but to act upon these ideals especially in the area of publishing. 
In many ways the response has been impressive. This comment is appearing in an Open Access journal that was developed precisely around this ethos. I have previously been involved in a discussion paper facilitated by the Open Anthropology Cooperative established by Keith Hart, another of the advocates in this realm. This cooperative looks to create an open equivalent of social networks and use this to advance free and open discussion in anthropology. Chris Kelty and others are involved in the blog openaccessanthropology.org. I don't think we have ever had such a ferment of ideas and ideals with new experiments in communication, debate, and publishing right across the board. Overall there is a sense that a subject called social anthropology might actually become just a little bit more social thanks to the positive appropriation of new communication media.

At another level it could be argued, I think correctly, that my intervention in Anthropology Matters was deeply conservative. This is because while it advocated an escape from commercial considerations in publishing, it remained wedded to a rather formal and established concept of scholarship and peer review. Indeed, in some ways by appealing to the most established scholars and luminaries in the field, it entrenched those criteria of adjudication. This was entirely deliberate and not a stance that I would wish to change. It seems to me that radical developments in the area of how we publish should be simultaneously associated with conservatism about what we publish. Otherwise we would, I suspect, quickly destroy the very thing we are hoping to create.

At the expense of what is clearly a rather opinionated statement about a neighboring discipline, I would suggest that when cultural studies first developed it confused two rather different things. It radically opened up the possibility of what could be subject to academic interest. It was surely right that anything from swimsuits to rap music to fanzines, even if quite transient, should be legitimate subjects of university research and discussion. But this insistence on broadening the world of scholarship was matched by the sense, given by the cultural critiques of that time, that the notions of authority-implied by terms such as scholarshipwere outdated and we needed to entirely free the world from such conservatism and allow pretty much anyone to say pretty much anything about these topics. As a result this nascent discipline quickly gained a sense of excitement but also lost the reputation for high quality academic work. By contrast, in the area of material culture studies within which I research, we insisted that we, too, wanted to broaden the sense of what anthropology could study, including many of the same areas being explored in cultural studies. But I insisted that all my students carried out quite conventional periods of extended fieldwork with the appropriate language skills that would pass the criteria of scholarship of any branch of anthropology. The aim was to retain the respect of peers even while engaged in what others at that time saw as new and suspicious subjects of inquiry.

There certainly are arguments to be had as to what constitutes scholarship and good or bad anthropological work, and I am happy to experiment with more popular forms of writing, for example, in order to reach wider audiences. When faced with the kind of innovations that followed the auto-critiques of Marcus and Fisher (1986) there is a need to carefully discriminate between the results. Just to take one example, the idea that the researcher might want to say more about how they came to make certain claims about the population they were studying by exposing more of the process of fieldwork, or note taking, or the creation of their analytical stance, can be argued to enhance scholarship and the aims of 
anthropology. But when this becomes the main focus of a publication to the detriment of our traditional self-effacement in the cause of being genuinely interested in other populations and not just in ourselves, then this trend may be rather less welcome.

The crucial point is that for Open Access publishing in the discipline to succeed it needs to be directly associated with clear, explicit, and conservative canons of academic judgment. Right now the key battle is to ensure that we overcome an absurd situation where being associated with some commercial brand-which is what most publishers today are-should be displaced by anthropologists working as their own peers to create more accessible modes of dissemination and discussion, while retaining their own criteria of adjudication. As I understand it this is precisely the ethos of the journal $H A U$ itself, as conservative in its view of scholarship as it is radical in its view of access. Fortunately we seem to have a long legacy of being stridently critical of each other's work, which has served us well in the past and should continue to do so in the future. But clearly this is in direct contrast with certain postmodern ideals, since it retains a clear responsibility for claims of authority and process. The difference between the technological ability for self-publication, which thrives in blogs, but is not subject to process, contrasts with the disciplinary interest in creative commons publishing that remains subject to academic review.

Conservatism over scholarship need not imply conservatism over any other form of innovation that does not threaten that reputation. An example of this may be the form of publication. When Don Slater and I published our book about the Internet (Miller and Slater 2000) we put all our illustrations online and only the text in the book. We naively assumed that within a year or two everyone would do this. We had realized that online meant you could have sound and music, animation and video, and loads of illustrations beyond just the photos one could put in a book. We originally put up whole websites to illustrate our arguments. Actually, this failed and the site proved impossible to maintain for a whole set of reasons. We were also wrong in that pretty much no one else followed our example anyway. But more than a decade has passed since then and by now these ideas surely ought to be more viable. So on the issue of what content we publish and where and how we publish it, I would submit that anthropology has been far too conservative. There is an argument that scholarship in the sense of our ability to more fully and accurately convey our research results and the evidence behind our arguments would only be augmented by a more adventurous attitude toward the way in which we disseminate and illustrate field research in the future. There are clearly genres within anthropology where we have failed to properly convey or disseminate our results because we have ignored the potential to use sound, animation, and other expressive genres that can be placed online to complement written texts. I hope that this will change within the next few years and suspect that many of us would be interested in experimenting with such new forms of online dissemination in the near future.

The debate that prompted this comment was, however, directed at the third element in my title. It had not occurred to me that the arguments around Open Access would surface under a rather different semantic field (which is that of Digital Anthropology) but in February 2012, following discussions associated with the US based AAA a largely US dominated blog at Savage Minds (Thompson 2012) considered developing an Open Access trajectory under the auspices of 
Digital Anthropology. As it happens I had just finished arguing the precise opposite, for reasons I will now briefly reiterate.

Three years ago I went to my university and asked if we could start a new program called Digital Anthropology, which would become, as far as I was aware, the first such program (though there was already an exciting program led by Michael Wesch at Kansas State under the title of digital ethnography which focused on YouTube). I fully admit that the initial reason was simply pragmatic. Material culture had become just too successful as a program in terms of student demand. I saw there was an increasing tendency to write dissertations on topics concerned with digital technologies so it seemed to make sense to hive this off and expand it in its own right. Perhaps not surprisingly this program attracted among the most enthusiastic students in the department. But after a while I came realize that there was a problem, or at least I had a problem, with this enthusiasm and I am at least partly to blame for this.

The reason these students are enthused is because they are in thrall to the dynamics of the digital. Every week there is some new device or discussion, and on their Facebook pages they post incessantly about the latest thing. As a private individual I share some of that. I used to watch TV programs with titles such as Tomorrow's World. Today I look forward to The Economist's Technology Quarterly, I like trying out the latest apps and devices, as do many others. But my presumption about the excitement of Digital Anthropology had never been that. What I assumed would be exciting (because as an academic this is what excited me) was not just working with the latest digital intervention but rethinking the very nature of anthropology: how the digital might make anthropology exciting, but more than that, significant. I had just sort of assumed as obvious that this would show how anthropology is even more central to contemporary academia and indeed contemporary intellectual thought than ever before.

The students, at least initially, do not see this at all. For them anthropology is just another device for exploring the digital. I took the blame for this because as I mentioned my advocacy had been pragmatic not intellectual. What was lacking was any attempt to clearly articulate the intellectual argument for Digital Anthropology and to demonstrate that far more exciting was the way it reinvigorated anthropology itself. So in the last eighteen months together with Heather Horst we have edited a collection from many of the people we consider to be the best anthropologists in this field, who have been working on these issues with respect to a wide gamut of concerns ranging from issues of disability, gaming, digital divides and development, media in the home, and the impact on politics (Horst and Miller 2012).

In the introduction to this volume (Miller and Horst 2012) six basic principles are outlined that try and turn this issue into a focus on the transformation of anthropology rather than just the interpretation of new technologies and their consequences. The first of these looks to the dialectical nature of digital culture as all culture. It starts by suggesting there is a clear potential definition of the digital, which is simply everything that can ultimately be reduced to binary code, that is bits consisting of $0 \mathrm{~s}$ and $1 \mathrm{~s}$. The development of binary code radically simplified information and communication, creating new possibilities of convergence between what were previously disparate technologies or content. It has meant that we can more easily produce, reproduce, distribute, and supply. So this act of reduction was simultaneously a huge act of expansion because these new 
technologies of communicating and replicating resulted in far more diverse cultural forms in the world. Just think of the entire online world that did not previously exist but equally the way digital technologies have facilitated creativity in most offline worlds. The term dialectic here signifies this simultaneity in the development of abstract universalism represented by base line 2 , and the profusion of new specificity and particularism represented by digital cultural forms.

The introduction goes on to suggest that if the digital can be unambiguously defined as a reduction to base line 2 , then there seems an obvious precedent that has been discussed by anthropologists for decades. This is the previous reduction to base line 10 that is found in most modern versions of money. At this point we engage in a debate over the work of authors ranging from Georg Simmel to Keith Hart around the anthropology of money and examine in what ways this might help us to develop an anthropology of the digital. Money can equally be considered to be a moment of dialectical transformation. What this means in practice is that analytically we can be orientated toward money at its moment of universalism and abstraction as money itself. Or, as Simmel (1978) argued, we can look to the huge quantitative and qualitative rise of differentiated material culture that moneylinked to industrial production-had created as the world of commodities. Much of my own work on consumption (Miller 1987) was an insistence that we look to that end of the dialectic, the new specificity of commodities, and not just the new abstraction of money.

If we now turn to the initial anthropological response to the rise of Digital Anthropology we can see the same conundrum. Most of the early work has emphasized the more abstract and universal aspects of the digital. The authors I mentioned above such as Coleman, Karanović, and Kelty are primarily concerned with the universalistic ethos that can be associated with open source. It is the overwhelming emphasis on this end of the dialectic that has led to the very possibility that anthropologists might conflate the terms Digital Anthropology with debates over Open Access. I would like to suggest that this really only touches on one side of this coin. Just as I prefer to consider the implications of money in terms of the vast rise of differentiated consumption, so also there are reasons for turning our gaze to the other end of the consequences of the revolution in digital technologies.

One of the problems of a focus on processes such as open source is that this is extremely technical. One study discusses the implications of research suggesting that only 1.5 percent of the geeks involved in open source activities were women, making it one of the most extreme examples of gender discrepancy in this day and age (Leach, Nafus, and Krieger 2009: 66). Even in much less technical areas, a report suggests less than 15 percent of those who contribute to Wikipedia are women (Cohen 2011). Women seemed less likely to embrace what was perceived to be a rather antisocial commitment of time to technology required of radical activism. Utopian ideals may not be the best models for effective changes in practice if the concern is with the population as a whole. The problem is similar to one when political activists advocate utopian ideals to overthrow political authority based on the assumption that everyone wants to spend their time as involved in political issues as they are, only to find that people cede political freedom for the very bad but very common reason that they cannot be bothered or have other priorities (such as parenting their children). 
In line with this argument, I proposed as my model for the vanguard of digital anthropology a group that are pretty much the exact opposite of the technophiles of California open source activists: the technophobes of the Philippines. More precisely, a bunch of Filipina mothers working mainly in domestic service and the health sector in the United Kingdom who have taken up with new communications media mainly because they have children left behind in the Philippines. Many of these people only very recently learned to type or purchase computers, and by and large see such digital technologies as male, oppressive, foreign, or all of these. They are typical of those who would reject open source alternatives if they were one iota more demanding than commercial versions. In a recent book (Madianou and Miller 2012) written with Mirca Madianou, we suggest these technophobes are the vanguard of Digital Anthropology.

Thanks to these women, Madianou and I were able to arrive at what we considered to be a genuinely new understanding of the consequences of these new digital communication media that we called Polymedia. This is not the place to outline Polymedia as a theory, but in a sentence the point was that what had happened was not simply a change in technology but a resocializing of media and a new shift towards normative moralities of media usage. These ideas derived from a study in which we first worked with the mothers in the United Kingdom and then subsequently travelled to the Philippines and talked to their children about how these new media had changed the very possibility of being a mother. It should not be any great surprise that the Philippines can be regarded as in the vanguard of a new media usage since there was an obvious precedent. As has been chronicled by Pertierra and others (2002), the Philippines is globally recognized as the so-called capital of phone texting. From its early introduction through today, more texts are sent per person in the Philippines than anywhere else in the world. Texting soon became central to the formation and maintenance of relationships, and was also claimed (with some exaggeration) to have played a key role in overthrowing governments. Texting is a prime case of a technology intended only as a minor add on, whose impact was created through the collectivity of consumers. Poverty and need drove these innovations in usage, not merely the affordances of the technology. Filipina mothers are at the frontline of Digital Anthropology not because they care about technology but because they care about their children.

The significance of this example is that these Filipina mothers (as technophobes) are the last group to advocate open source or Open Access on ideological grounds. They just want the cheapest, easiest media they can get their hands on in order to focus on the issues of mothering. They are one of the many victims of a political economy that creates conditions for separation that they are desperate to overcome. This should surely be the heart of a new Digital Anthropology, a concern not just with technology, nor indeed just with anthropology, but rather with the welfare and creative response of the diverse populations of users of these technologies as encountered through ethnography. We need to pay at least as much attention to consequences as to the creations of these technologies.

For these reasons it would seem entirely misguided to narrow the term Digital Anthropology to areas such as methods, or the ethos of Open Access. Digital Anthropology should rather rethink the very nature of anthropology itself in the light of our contemporary world and its consequences for the welfare of populations across the globe. Although there is some overlap, it is largely a separate question about how best to progress toward Open Access publication- 
and in tandem with that, where appropriate, online publication-while retaining those processes, which secure authority and reputation for anthropology and anthropologists.

\section{Acknowledgements}

Thanks to Alex Golub for comments on the draft of this paper, and to Heather Horst the coauthor of those arguments developed for the book Digital Anthropology.

\section{Responses}

\section{Comment on Miller}

Amita BAVISKAR, Institute of Economic Growth, Delhi

Daniel Miller's call for scholarship which is conservative in its view of quality as much as it is radical in its view of access is important for distinguishing between two often confused issues: academic standards and Open Access. His comment makes it clear that the two are not mutually exclusive. According to Miller, "the crucial point is that for Open Access publishing in the discipline to succeed it needs to be directly associated with clear, explicit, and conservative canons of academic judgment.”

The "canons of academic judgment," contentious as they are in Europe and America since the challenge to the reign of Dead White Men, are even more questionable in India and other parts of the South. For researchers whose first language is not English and who are not rigorously trained in the discipline's concepts, modes of analysis, and presentation, it seems impossible to write up their work such that it speaks to contemporary debates (and is therefore likely to be accepted by a peer-reviewed journal or reputed academic press). Yet the work itself is worthwhile and rich: the intellectual aim is passionately felt, data is gathered with diligent sincerity, and intense thoughtful labor expended on the task of writing it up. Equally important, the research deals with concerns that are more immediate and proximate to the researcher and rarely count as "cutting edge." When working as coeditor of Contributions to Indian Sociology, charged with upholding the standards of a internationally ranked journal while working much of the time with India-based researchers, we dealt with this dilemma by treating editing as a form of pedagogy-teaching junior scholars the basics of article writing, but our job was more akin to translation-rendering the concerns and style of vernacular Indian anthropology into a more universally recognizable disciplinary mode. However, our attempt to bring our authors in line with the universal standard as set by the Anglo-American academy may have actually done them a disservice by not helping them present their work in a manner that compelled the so-called "canons of academic judgment" to be challenged and reworked. The opportunity to "provincialize Europe," to use Dipesh Chakrabarty's (2007) phrase, remained untapped. 
Academic standards for Open Access publications are indeed important, but when those standards are based on the imposition of a canon, they run the risk of reproducing online the inequalities that pervade the paper-publishing academy. This is all the more a problem because it discriminates against emerging forms of ethnographic documentation and analysis that use digital technologies to transcend the language barrier. At Goa University, for instance, anthropologist Alito Siqueira's students write video articles, which have the added advantage of being accessible to the communities with whom they work. Despite these merits, these videos are not recognized within the conventional genre of scholarship in the discipline. The potential of digital technologies for creating and circulating research that speaks to different concerns and broader audiences requires not a reiteration of the canon's academic standards, but a re-engagement with the issue of how standards are set, challenged, and changed. Miller's comment provides us with renewed impetus for doing so.

\section{A response to Daniel Miller: Open access, scholarship, and digital anthropology Don BRENNEIS, University of California, Santa Cruz}

I'd like to thank Daniel Miller for his bracing and comprehensive paper, Giovanni da Col for inviting me to be among the respondents, and $H A U$ for its innovative contribution to collegial conversation and scholarship. Miller makes a convincing and densely packed argument that there are at least three distinct if intermittently entangled themes at play here: Open Access, peer evaluation as a guarantor of scholarly quality, and the quite broad and generative terrain of Digital Anthropology. He notes quite effectively that we should analytically distinguish among these three threads; most significantly, perhaps, he argues that Digital Anthropology is not reducible to questions of Open Access.

I want to highlight several issues in my response. First, I want to support Miller's claim that Digital Anthropology should be understood to extend well beyond Open Access issues, however salient and compelling a theme that is both for many individuals and communities, and for many anthropologists focused on digital worlds. Certainly the socialities of virtual worlds, the affordances of new communicative technologies and their subsequent social lives among unexpected actors, and digitally catalyzed and enabled compositional resources and the transformations of cultural performance they help shape are all generative sites for such research and analysis.

At the same time, I'd like to suggest that an anthropological approach-in part digital, in part more traditional-that attends to complexity and variation in the world of scholarly publication at the heart of Miller's concern can add further to the discussion of Open Access as well. As one example, not all publishers are the same: within anthropology some scholarly associations have sold their journals to commercial publishers, while others, including the AAA, have maintained ownership of the journals, while using commercial presses for publication and distribution. And different publishers pose different problems and opportunities for thinking about more Open Access; mapping the specific landscapes of ownership, pricing, and the practices and determinants of editorial policy seems important. There is also great cross-national variation vis-à-vis support-financial as 
well as ideological-for Open Access. A recurrent theme in several years of transnational editors' conversations at the AAA annual meetings has been that some national governments (for example, France) are often generous in subsidizing the most Open Access possible for some journals, while others (especially the United States and United Kingdom) may be moving towards unfunded mandates in this area-but don't directly help pick up the tab. As a final example, the processes of review, editing, and publication are in many ways invisible but not frictionless. Peer review, while voluntary, requires coordination, and copyediting comes at a price. Less visibly, perhaps, the coding and preparation for searchability that contribute to the effectiveness of online publication has become increasingly significant as a cost. This metadata matters, both for helping guide readers through the welter of available materials and for contributing to the possibility of citation, an increasingly (if irritating) emergent criterion in evaluation. New processes such as peer response (post publication, as an alternative to peer review) and crowd coding (as an alternative to expert coding) are emerging, but, for reasons Miller has outlined, they may have unintended consequences for the perceived integrity of scholarly value. As with most issues with which anthropologists concern themselves, Open Access implicates a heterogeneous and at times unpredictable social, economic, and institutional terrain. Bringing anthropology-digital and otherwise-to bear even more closely upon its specifics might help us collectively move closer to realizing its possibilities.

\section{Open Access, scholarship and anthropologies: Comment to Daniel Miller Carlos Fausto, Museu Nacional, Universidade Federal do Rio de Janeiro}

When we founded Mana: Estudos de Antropologia Social in 1995, there did not even exist the expression Open Access journal. I remember people starting to talk about going online, but we did not even consider this possibility. We were three young, recently employed anthropologists, who admired the Anglo-Saxon standards of publication. At the time, we adopted a number of editorial standards of which the most definitional were to peer review all articles, to publish only unpublished manuscripts, and to publish always in Portuguese. Over the years, this strategy proved successful, and we put in print pieces by Sahlins, Descola, Bourdieu, Strathern, Chartier, Becker, Hugh-Jones, Overing, Hannerz, Kulick, Robbins, de Pina Cabral, Crapanzano, Latour, to cite just some non-Brazilian anthropologists who contributed to Mana.

It took us more than ten years of regular publication to be indexed by ISI Web of Knowledge (Thomson Reuters). Much earlier, however, we went online and Open Access. Things moved fast in the 1990s and, within two years, we were invited to integrate the recently created platform SciELO (Scientific Electronic Library Online), developed by a partnership between Fundação de Amparo à Pesquisa do Estado de São Paulo (FAPESP) and the Latin American and Caribbean Center on Health Sciences Information (BIREME). The first uploaded issue was Volume 2, Number 2, in which Viveiros de Castro's article on perspectivism was originally published.

Since the beginning our concern was with publication, that is, with making public. It seemed logical to us that if there was a new way of giving access to the 
results of scientific work, we should go for it. In Brazil, almost all research is sponsored by public money. It would make no sense to receive public resources for research and not make public the results of it. So it was noncontroversial at the time. The controversy exists today, though, as Brazilians publish more and more in major journals belonging to big conglomerates of scientific publication. In these cases public money cannot be immediately converted into public knowledge. One must top up with more money to have access to it. This is a vicious situation, since the conglomerates' profits depend on both the public money poured into the system and the gift-giving morality of peer review. Authors and reviewers do their jobs for no compensation beyond the publication itself. We are not talking here about the small business of publishing never-sold-never-read books, but about conglomerates that privatize public virtues. There must be a limit to it.

That said, I do not see any incongruence between Open Access and scholarship. The risk of bad scholarship depends on other factors, such as the current constraints that stem from commercial and not from academic criteria. I am thus basically in accord with Miller's arguments in regard to the advocacy of Open Access for anthropological writing and the necessity of maintaining the credibility of the anthropological work. I find, however, his notion of scholarship a bit partial, and would like to see it further developed. Is it only about peer review and a respectful editorial board? Are there unambiguous universal standards for judging quality?

These questions may sound a bit naive (and in a sense they are). But they do not spring from an all-is-relative-and-everything-is-politics kind of mentality. My point is that Miller could also have used the term dialectic to explore the other side of universality in scholarship, as he does when discussing Digital Anthropology: "The term dialectic here signifies this simultaneity in the development of abstract universalism represented by base line 2, and the profusion of new specificity and particularism represented by digital cultural forms." Paraphrasing his argument in terms of our questions, we should ask: First, with the development of abstract universal scholarship, what kinds of particularism proliferate? And second, which among these should be counted as pernicious, and which should be considered creative innovations?

The mere abstract defense of scholarship obscures both the nonacademic asymmetries existing in most anthropological journals and the tendency of these journals to emulate a single and homogeneous standard. Anyone who is not a member of US or UK institutions knows how many barriers exist for successfully publishing in major journals in English (the scientific lingua franca and also the language of the Center). The problem could be synthesized through the acronym WRWWL (Who Reviews Whom in Which Language), which I once employed in a letter to the editor of a well-known journal. At the time, I had already been invited by the reviewers to cite a large number of authors based in institutions of the same country as the journal.

WRWWL is a mnemonic acronym to remind us of the necessity of questioning practices that reinforce not only the citation power game that has become a key criterion for successful careers, but also of examining the concentration of citations within certain parts of the anthropological network. We must be aware of the risk of cutting the network in a way that creates a perverse particularism, insofar as local-national preferences come to appear as the result of the application of a universal rule. One just has to peruse, for instance, the Annual 
Review of Anthropology, where one expects to encounter articles that survey state of the art research on chosen topics, to discover that the number of references to texts in languages other than English can be counted on one hand.

Is this a complaint stemming from a (semi)peripheral condition? In a sense, it is (and I see no problem in admitting it). But I have been playing this game for long enough to feel comfortable in affirming that this should be of general concern. In a convoluted way, such particularism converted into a universal rule leads to the homogenization of anthropological thinking. Some locals become global, while others remain very local. How can we then tell apart what is bad anthropology from what is part of another tradition of thought and other local conversations? How can we defend basic quality standards without being too conservative and weakening our capacity for innovation?

These are central issues for our current discussion. We should be mindful of the very word scholarship. It pertains to an academic world that is mostly closed upon itself, and points to a sociality of monasteries and colleges. I am not against it as long as it is combined with another term, also definitional of our identity and practice: intellectual, a word that relates to understanding, and implies an engagement with the world and the public arena. We do need scholarship, but we also need intellectuals from different traditions and languages to make our knowledge relevant, diverse, and completely public. This is what I think $H A U$ seems to be about.

\section{Separate but entangled; peer reviewed but not conservative} Kim FORTUN and Mike FORTun, Rensselaer Polytechnic Institute

Daniel Miller is right in arguing that many discussions about Open Access conflate different issues: The argument that scholarly publishing should be available to all, toll-free, and uncensored by commercial interests, is separate from arguments that scholarship should be peer reviewed. Separate as well are arguments about how anthropologists should study digitization and its consequences. There are three issues here, and sets of questions-about the medium, means, and content of contemporary scholarly publishing at its best. These are indeed separate, but also entangled.

The central issue, in our view, is whether peer review should be associated with a conservative approach, as Miller contends. Peer review-evaluation within a community of practice-is critical to scholarship, whatever the field. Scholarship is a collective practice; it takes a village, so to speak, for knowledge production to become scholarly. And all villages, we know, are in history. Scholarship advances through a productive oscillation between testing with established techniques, and cultivating openness to what cannot be explained with established concepts and techniques (as historian Hans-Joerg Rheinberger [1998] has shown for the sciences). Scholarship thus needs to be both conservative and open-which may be "postmodern," but does not entail an abandonment of "authority and process." The challenge for scholarship, that $H A U$ responds to so admirably, is to figure out how to be open collectively, developing new modes and criteria of evaluation appropriate to changing conditions. Anthropology as a community of practice cannot prosper if all it 
encounters is judged with "established concepts" of what is proper and valuable; the village should not be taken out of history. Instead, we must deliberate and figure out how to respond to changes in the landscape, new problems, new technologies, and new connectivities. Open Access scholarship both creates these new connectivities and has the potential to support enriched deliberation about their implications.

Open Access publishing thus should become entangled with calls for changes in peer review, not to gut it but to refresh, strengthen, and expand it. Open Access and digital publishing create possibilities-including the possibilities of postpublication peer review-for extending and deepening collective engagement with and evaluation of scholarly work, making collaborative production of knowledge much more realizable. This is the goal and value of peer review, and Open Access publishing has the potential to reanimate it. Through Open Access publishing and digital technologies more scholars, and more diverse scholars (and publics), can engage and help evaluate a given piece of scholarship, at many stages of its development and circulation. In process, habits of pitting US dominated approaches against those in the UK may be deflected, helping realize the promise of a world anthropology in which differences between scholarly communities become a resource and the basis of productive exchange.

Engaging the digitization of everyday life-for Filipina mothers, among others-also calls for new modes of collectivity and peer review, which open access publishing can support. From Shakespeare studies to genomics, digitization has enabled new comparisons and recombinations, allowing scholars to consider diverse data sets and analyses side-by-side, generating knowledge through juxtaposition. Documentation and analysis of how the Philippines has become the most texting country in the world can thus be considered alongside analyses of texting practices in Nigeria, China, and the United States-in new, deeper ways that digital technologies allow. Through these new modes of work, anthropology can better authorize and develop its own genealogies and concepts and avoid the "intellectual suicide" of which da Col and Graeber (2011) warn, in which anthropology would neglect its own intellectual inventions and rely entirely on imports.

Open Access anthropology can animate new modes of peer review, helping anthropology engage a range of emergent phenomena, including digitization. Such an anthropology would build on its past, but also would be experimental-open to the study of new phenomena, actively seeking and inventing new methods and theories, drawing new peers into the process of collective evaluation.

\section{Comments on Miller: Open access, scholarship and digital anthropology Alex GOLUB, University of Hawaii at Manoa}

Daniel Miller's comments are very welcome to me, as someone with one foot in the academy and the other in the fertile, turbid waters of the Internet. Much of what he says echoes the current state of the art among bleeding-edge thinkers involved in Open Access and Digital Anthropology, and it is gratifying 
and important to see establishment figures such as Miller articulating them as well.

Miller argues that moving anthropology's publications online ought not entail rethinking our genres from scratch. I couldn't agree more. We can see an emerging (and friendly!) divide in anthropology between students of the Rice Circle (Faubion and Marcus 2009) such as Chris Kelty and more orthodox anthropologists such as Miller and myself. For the Rice Circle, the Internet represents a space in which to continue the genre blurring experimentation that their mentors George Marcus and Michael Fischer initiated on in the 1980s (Marcus and Fischer 1986, Fortun 2011). For the $H A U$ circle, the Internet represents a place in which (as Marshall Sahlins might say) anthropology can become more itself than it ever was before: a shift of format that allows the realization of our scholarly ideals, not their dissolution. This is also the position of Savage Minds. We see the Internet as the location for a proliferation of new digital genres that ride alongside-but do not replace-existing modes of scholarly production. We are, as we say, the digital equivalent of the bar at a conference venue, not a replacement for the paper sessions.

That said, I do want to sound two notes of skepticism regarding Miller's formulation of "Digital Anthropology." First, his narrative is of a gradual broadening: Digital Anthropology originally meant studying open source and now it means a broader reformulation of the digital as a whole. Studying nontechnophiles is meant to be theoretically satisfying. I am not convinced, however, that this narrative holds us. Even a cursory look at early ethnographic studies of usenet, MUDs, and other digital worlds (Kendall 2002, Dibbell 1998, Cherny 1996 to name just a few) shows a concern with issues of gender and the experience of nonprogrammers online. Vincente Rafael's work on cellphones in the Phillipines was conducted before Biella Coleman's PhD thesis was completed. I could go on, but I hope I've made my point: ethnographies of the digital have never only or even largely been about open source, which makes studying something else an interesting but not novel proposition.

It could perhaps be argued that the work I've cited is not anthropology strictly speaking. But such a position begs the question of how Miller will relate Digital Anthropology to the decades of ethnographic work done in other disciplines in a way that keeps anthropology from seeming naive, cloistered, and intent on reinventing the wheel-which is what I fear they may think of us.

Second, I don't see the utility of an overarching sphere called Digital Anthropology. After all, how much analytic purchase do we get on all anthropology written prior to Miller's article if we were to call it "analog anthropology"? Like the analog the digital is too big a fish, in my opinion, to fry. As sociotechnical networks proliferate, it becomes less and less appetizing to use one overarching label to study them-as was done unsuccessfully in the 1990s via various i-, e-, and cyber- prefixes. Rather than retheorizing an object domain that grows more unruly every day, we ought continue to expand the analytic categories we use to comprehend both analog and digital phenomenon. We must be profoundly delighted by the digital, but also supremely unsurprised by its congruence with the material in our existing ethnographic encyclopedias. 
Such an approach is (I'm sure Miller would agree) what really separates anthropology from other, more breathless disciplines that study the digital. And as any reader of $H A U$ implicitly asserts just by downloading Miller's piece, it is this insistence on properly ethnographic theory that gives our discipline enduring worth.

\section{Response to Daniel Miller: Open access Sarah GREEN, University of Manchester}

Miller points to the twin pressures on academic publishing that have stimulated the dramatic rise in support for Open Access: the rapid/rabid commercialization of the publishing world-what might be called "savage publishing," to borrow from Gregory (1997)-combined with increasingly demanding publication requirements to secure a university post. Miller passed over both quickly, presumably because there is not much more to say than has already been said. Perhaps, though simply noting the increased commercialization of academic publishing leaves out the wider context: the whole academic enterprise, in the Anglophone world at least, has become more commercial over the same period, and more proprietorial about intellectual work (McSherry 2001). Moreover, university libraries, once the main customers for most academic books, have significantly reduced their purchases; undergraduate teaching and the introduction of Virtual Learning Environments (VLEs) have radically altered the way students access and read course materials; and many governments are reducing their support for higher education. In short: the academic context in which publishers once sold books and journals no longer exists.

Equally important is the increased use of auditing techniques in the academic sector, whether these involve elaborate government-sponsored events such as the Research Excellence Framework in the UK (REF), or the increasingly widespread daily use of various digital technologies available online. These provide an array of methods to classify, evaluate, and measure journals, publishers, and texts, an aspect of the "rise of the digital" that Miller does not address in his suggestion (with Mirca Madianou) that "technophobes are the vanguard of Digital Anthropology." There are plenty of technophobes among anthropologists, who are nevertheless rapidly learning the skills needed to use these digital technologies in their working lives. While it is possible for national audits such as the REF to refuse to use bibliometrics in assessing academic work, there is no escaping the daily availability of such data anymore. What could be called perpetual online auditing of academic work-citation scores, impact and influence assessments, Amazon sales ratings, Wikipedia entries, maps of the relative significance of scientific journals (see below for an example)-has made it impossible to avoid the logic informing digital modeling and database design in the academic sector today. This ubiquitous presence of twenty-four-hour-a-day ticker-tape data about academic activity makes Open Access important just now: it is entering that same digital field that has been flooded by those data, but with different thinking about the relation between authors, readers, and access. As Haraway (1985) noted many years ago, it is 
not the technologies that are the problem; it is the thinking behind them. Open access provides one way to think otherwise.

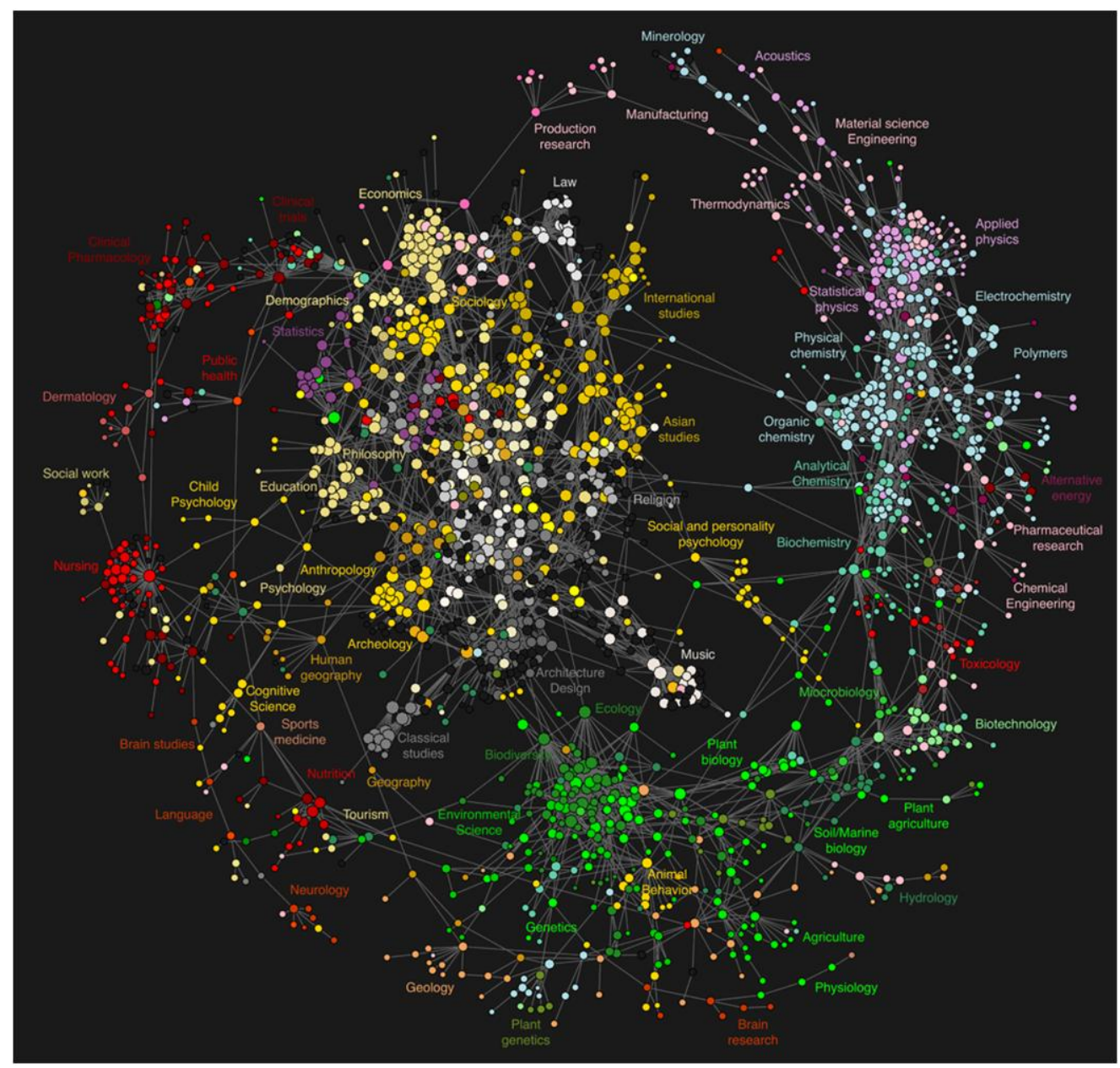

Image: Circles represent individual journals. The lines that connect journals are the edges of the clickstream model in $\boldsymbol{M}$ : Colors correspond to the AAT classification of the journal. Labels have been assigned to local clusters of journals that correspond to particular scientific disciplines. Source: http://www.plosone.org/article/slideshow.action?uri=info:doi /10.1371/journal.pone.0004803\&imageURI=info:doi/10.1371/journal.pone.0004803.g005\#

\section{Comment on Miller}

Chris KeLTy, University of California, Los Angeles

Is Open Access/free software about the creations and Digital Anthropology about consequences? Do we need more of both, just not together, as Daniel Miller would have it?

To explain digital anthropology, Miller invokes the figure of the technophobic Philippine mother who loves to text: "The significance of this example is that these 
Filipina mothers as technophobes are the last group to advocate open source or Open Access on ideological grounds. . . . We need to pay at least as much attention to consequences as to the creations of these technologies." It seems a safe bet. This Filipina mother doesn't care about Linux or Debian, she just wants "the cheapest, easiest media they can get [her] hands on in order to focus on the issues of mothering." She couldn't care less whether one uses a BSD license or a GPL license; she doesn't read journals published by Elsevier or agitate for Open Access; she doesn't belong to the EFF or Creative Commons. She doesn't know or care about device drivers or stack overflows, or DDOS attacks.

Well, it is perfectly possible that she might care what a DDOS attack is. In fact, I think she hears about it from her nephew and his friends. They wear funny Guy Fawkes masks when they go to protests. She herself likes the local community center for the free (as in gratis) wireless, to avoid the download fees from her mobile carrier. I'm pretty sure she listens to pirated music and uploads videos to YouTube; maybe she's angry that YouTube keeps removing them. Her daughter reads, or maybe writes Harry Potter fan fiction. Her neighbor fansubs (illegally creates subtitles) for Disney movies into Tagalog for her kids to watch. Once she used her phone to document an earthquake, or maybe it was an election disturbance. Maybe she (or her son, or her cousin) wants to "like" Abu Sayaaf or the New People's Army, but is afraid that Google or Facebook will report the family to the government. She wears a secondhand shirt with a picture of a cuddly penguin on it and the words Free as in Freedom on the back. And so on.

The point is that all these "consequences as to the creation of new technologies" are easier to understand if one understands the politics, practices, and "ideological grounds" of free software, or open source, or Anonymous, or the copyright wars. It is an error to assume that a study of free or open source software is a study of the creation of a technology, and one irrelevant to the lives of normal Filipina mothers. Texting might appear to be more real, or closer to lived experience, or less universalizing than a concern with the details of software and networks.

But texting is entirely too specific a practice to hang an anthropological analysis on. A digital anthropology should address how these technologies implicate people in global structures of intellectual property policing, information technology industry concentration, linguistic transformation, standardization battles that privilege some values over others, and the global reach of entertainment, telecommunications, and advertising corporations-all things that are lived, everyday. This was in fact the point of Anthropology as Cultural Critique (Marcus and Fischer 1986) and it is not in any way incompatible with paying close, careful attention to the everyday lives of people.

The figure of the texting Filipina mother could, I fear, play into a nostalgic desire for an authentic face-to-face anthropology in which texting is artificially restricted to a particular kind of phenomenological and social environment accessible to the ethnographer. This would be a loss, in part because it fails to investigate how texting literally teleports subjects into an alien world of technical, political, and economic structures-and most importantly, a world over which they have some power. That power comes from the fact that there is a transnational, politically engaged, technically sophisticated culture that is engaged in making the tools and technologies we use, and the infrastructures we inhabit, more just, more equal, and more free. This power is visible and understandable in cases such as 
free software, Anonymous, or the global battles over copyright, patent, and accessand the connections to the texting Filipina mother might emerge in a variety of surprising ways assuming an ethnographer is willing to look for them. Why deny that power to the Filipina mothers in favor of a gentler story of mothering and convenience?

\section{The value of open access publishing}

Martha MACINTYRE, The University of Melbourne

Daniel Miller's advocacy of Open Access online publication strikes me as a case of breaking down a wide-open door. I know of no anthropologists in Australia who oppose initiatives that enable publication and wide distribution of scholarly literature at minimal cost. The maintenance of scholarly standards through processes of peer review-and I would argue, careful and judicious editing-should not be a problem either. The majority of academic anthropologists remain committed to peer review as the means of ensuring high standards of scholarship, writing, and debate within the discipline.

The commercialization of academic publishing appears to be a fait accompli. Miller describes its effects appositely. University presses in Australia no longer publish many academic books. Some, such as Melbourne University Press (generously subsidized by the university) publish memoirs of politicians and notorious criminals rather than the works of academics-because they sell to a wider public. But from an antipodean perspective the effects of commercialization are even worse than they are in Europe or the United States. This is because very often overseas-based publishers consign anthropological research that has a strongly regional basis to the rejection basket, on the grounds that it will not sell internationally. In discussions with editors I have been told "Australia is of no interest to international readers" and "Melanesia doesn't sell." Yes, it is tragic that brilliant research and beautifully written ethnography can be dismissed on commercial grounds.

The online publishing initiative by The Australian National University, epress.anu.edu.au/ has been a great success. Books and journals can be downloaded free of charge and hard copies can be bought relatively cheaply. Like Sean Kingston's publications, the quality of editing, layout, and printing is high. The university adequately supports this enterprise and its editorial board is comprised of academics dedicated to the standards that Miller upholds. The site has heavy traffic. But for those anthropologists who are concerned about the dissemination of publications to the people whose lives are the subject of their study, it also enables people in the Pacific to have immediate access to publications.

The real problem identified by Miller is that of gaining from universities academic recognition for online publications. Every anthropologist I know who has looked at $H A U$ has been impressed-but this will not wash with university and government bureaucracies. While peer review remains sacrosanct, peer esteem is not significant unless it can be calculated objectively, by totting up citations. The corporatization of universities increasingly involves notions and calculations of cost and productivity, with auditing and assessing that bypass academic understandings of value. If publication is to count for promotion or gaining grants and 
appointments, it now requires more than ensuring peer review and editorial boards full of distinguished anthropologists. The ranking of journals by impact factor and the counting of citations have been embraced in Australia. Never mind that Elsevier and Thomson Scientific are proprietors of these Citation Index databases and, not surprisingly, exclude from their computations many journals that are published by small presses. Citations in books don't count; publications that don't make it to a Citation Index don't count.

Finally, it needs to be remembered that Open Access journals might be free to readers, but they still require the (usually unpaid) hard work of editors and reviewers, the skills of IT people to set up and maintain them, and access to the technology that enables online publication. In Australia, universities are increasingly unwilling to assist with the processes on the grounds that these are a cost.

\section{Open access, digital communication, and their unexpected outcomes: Comment on Danny Miller}

Atsuro MORITA, Osaka University

I agree with Miller's caution about the quality and value of current scholarship, particularly given the enthusiasm for new and emergent forms of academic communication. However, I would like to suggest another attribute of Open Access journals like $H A U$; that is, their capacity to broaden and diversify scholarship. Although I agree with Miller about the importance of maintaining the standard for academic work, I think some change almost inevitably accompanies new forms of academic communication for just the reason he so nicely illustrated with the case of Filipino mothers-that is, a new technology often invites unexpected users.

Readers can find an illustration of this point in the present comment itself. It might be unlikely in existing offline journals such as Journal of Royal Anthropological Institute for a young scholar like myself, working in East Asia and unknown in the British academic community, to respond to Miller's comment that apparently concerned the British situation specifically. Yet, precisely because of the opportunities for more inclusive academic dialogue afforded by resources like $H A U$, I can offer this response to Miller's well-taken critique. Regardless of their initial aims-countering commercial interests in academic publishing, for instancedigital innovations in academic communication often initiate conversations between hitherto unassociated scholars belonging to different communities.

Although Miller didn't mention the online journals' capacity to bring about new dialogues, it is apparently the central concern for many Asian scholars. For instance, unlike British colleagues, Japanese anthropologists do not see Open Access journals as necessary to counter expanding commercialism because most academic journals in Japan are still run completely on a noncommercial basis. Rather, what interests us most is the opportunity created by the online journals (and by writing in English) to engage in dialogue with overseas colleagues. There are a handful of Asian journals, including commercial ones, serving this purpose: to name just two, East Asian Science, Technology and Society published by Duke University Press with a subsidy from the Taiwanese government; and, an open 
access online journal NatureCulture headed by Japanese anthropologist Naoki Kasuga and just launched this year. Interestingly, contributions to those new journals with different purposes and institutional backgrounds often resonate and intersect with each other.

This intersection leads to a question concerning scholarship: if new academic communication media may create new relations among different academic communities, how can we be "conservative," as Miller prescribes, about the criteria of academic work? Different academic communities may have different criteria for good scholarship. Miller's call to be conservative is problematic because it may not be possible to separate conventions that contribute to a high quality of work from mere parochialism.

But I still prefer Miller's “conservatism” to the unreflexive endorsement of the freedom opened up by new media because it raises a serious practical question about how to deal with difference while seizing these new opportunities. How can we be conservative enough to maintain academic quality while, at the same time be flexible enough to sustain dialogue? I am sure that there is no simple answer to this question but it is one we must bear in mind throughout our daily practices of writing, reviewing, commenting, and editing.

\section{Comment on Miller}

\section{Carlo SEveri, Ecole des Hautes Etudes en Sciences Sociales}

Danny Miller presents three arguments. On the first ("Commercial considerations should not vicariously stand in the stead of what purport to be academic criteria. So there seems an overwhelming case to support and promote Open Access publishing”), I entirely agree. It is a good thing to use the Open Access publication for communicating, in a fast and costless way, the results of anthropological research. In France, a number of young scholars have founded very good online reviews (like Images Re-vues) or blogs (like Anthropoweb). Some prestigious institutions and publishers (including the EHESS, the ENS Rue d'Ulm or L'Herne) already offer online versions (Numilogs) of the books they make available in print.

The second argument presented by Miller, who proposes to use Open Access publication as "an escape from commercial considerations in publishing," while remaining "wedded to a rather formal and established concept of scholarship and peer review" is reasonable, but might contain an intellectual trap. On this point I agree with Carlos Fausto: peer reviewing certainly is a good way to maintain good scientific standards. However, as it is generally practiced by major journals in our discipline, it also implies a number of conditions entirely dictated by Anglo-Saxon criteria. To publish in other languages than English is very often considered a minor way to publish, and this is not acceptable. Many interesting things are currently published, for instance, in Portuguese, French, or Italian and the fact that English-speaking scholars are usually unable to read them is to be considered a failure of their education, not a "natural consequence" of an extravagant custom of French, Portuguese, or Italian scholars! My conclusion is that peer reviewing is a theoretically good principle, often badly applied. The ideal reviewer of our major journals should read at least two or three languages, a thing which was, and still is, natural for many European and non-European scholars. 
Let me now come to the third point: "Digital Anthropology" and the "ferment of ideas and ideals with new experiments in communication" that it can mobilize. Miller argues that the study of the many ways people use a "base 2" technology of communication can "represent specific challenges and create a new significance for the discipline of anthropology itself." I have no doubt that the study of this kind of communication, with its specific networks, ethos and traditions represents an interesting field of research. But I have also the impression that in Miller's text and in many other debates the idea of being digital is used not only to designate a specific field of research, but also a as a way to qualify theoretically the kind of anthropology which uses, in many different ways, the network. I think that this is a mistake. Despite appearances, communication (and the kind of thought it implies) is not qualified by the technique of storage and representation of information it uses. In a famous book, Jack Goody (1977) has claimed, for instance, that organized "lists of items" (and the kind of taxonomic thought that they imply) can only be realized where alphabetic writing is used. I have been able to show (Severi 2007) that this is simply untrue. The representation of lists of names, through visual salience and logical order, can connect (for instance in Native American societies) with various forms of oral traditions. In these cases, tradition generates very complex forms of iconographies, and other sophisticated non-Western "arts of memory." Storing images in memory, and the kind of "composition in mind" that it requires, involves a number of thought processes, related to the identification of visual salience and to the establishment of orderly sequences, not to a specific technique of the representation of language. The memorization of elaborated and extended lists of names is not logically linked to the invention of writing.

So it is, in my view, with digital techniques: there is no direct relation between the "base 2" ways to store and send information and the inherent logic of communication. "Base 2" might be an element playing a role in the definition of the sociological conditions of the propagation of a certain kind of content, not a way to define the logic of communication.

In the same line, I would argue that there is no direct link between the fact that a journal is published in Open Access and the kind of anthropology it publishes. In short, $H A U$ is welcome not only because it is published in Open Access (with all the political consequences of this choice), but also because it defends an interesting theoretical perspective. There is nothing digital about it.

\section{Reply}

Daniel MILLER

First my warm thanks to all who have given the time and thought to write comments. I will start with a brief response to each. With regard to the subsequent conclusion, I leave the wider defense of Digital Anthropology to the introduction to our book (Horst and Miller 2012) with that title. My emphasis will instead be on how to achieve Open Access.

With respect to Baviskar, I would share the hope that Open Access is not just a technological term. The political desire for increased access should equally foster a 
more global outlook. Anthropologists should seek to level the playing field for publishing, shifting the balance of power away from areas that have been historically dominant. I also agree that it may be new forms of dissemination that could be in that vanguard, leapfrogging traditional genres.

Brenneis provides a sobering response. As he implies a simplistic or dualistic Us and Them stance, he ignores the complex middle range of publishing associated with anthropological organizations and national subsidy. Changes will inevitably have to be ad hoc. There will be unintended consequences of Open Access (some negative), and our conversations therefore have to remain lively and responsive.

I believe Fausto brings out a major flaw in my argument: that conservative peer review can lead us into esoteric performance of cleverness and stymy respect for more popular outward facing publications. If something is online but written in an obfuscating style that excludes most interested readers, in what sense is that really Open Access? I happily concede this point-also that this can reinforce asymmetries of power and the imperialism of English.

One could not but be sympathetic to the Fortuns' point about also being open to changes in review processes. I guess my hunch is, however, that the baby is Open Access and it would be a pity to muddy the bathwater of review right now. Those who oppose Open Access will certainly use the argument that it will dilute the standards of review. But I do wish that the Fortuns are right and I am wrong here, since their vision of experiment and less parochial engagement is an exciting one.

Golub is well informed about the trajectories leading to these debates, noting works that some of us may have missed. But against Golub's skepticism, our introduction to the book Digital Anthropology does make an argument for this as a field of study. Coming as I do from material culture studies I hope that using the term anthropology would not limit interdisciplinary engagement and in particular respect for the wider practice of ethnography in the development of that field, something Golub is quite right to highlight.

Green wants to broaden and finesse our understanding of the problem. She is right to insist upon both its complexity and dynamism. But I make no apology that my paper is focused on the trajectory that leads to what should be the most promising route to actually doing something about this. It is hard not to be ambivalent about her own wonderful diagram, that we might refuse as abstracted visualization but welcome as it happens to place anthropology near the center of the clickable universe!

I am not sure why Kelty would imply that I am unaware of the way Filipina mothers are impacted by the digital political economy. The reason I am researching them in the first place is a separation from their children that results from their inextricable involvement in global political economy. The point is not to romanticize traditional fieldwork, but to argue that in our fascination with issues of power and global engagement we are in danger of once again reducing populations to passive recipients. It is probably only anthropology that gives voice to their creativity as coproducers of our digital world and can appreciate how and why this may indeed derive from a primary concern with being a mother.

The Australian National University initiative described by Macintyre sounds like one to be emulated. As she notes, it is crucial to address and radically transform the power that today unfortunately has accrued to audit, ranking, and 
citation as well as review. That does mean working within and not against universities, national and transnational organizations that alone have the capacity to accomplish such a major shift in acknowledgment and respect.

Morita is surely right to suggest my examples were too parochial and anthropologists-of all people-should be ready to learn from comparative situations including those of East Asia. It also seems right that new formats may help to develop wider engagements from which we would benefit and increasingly transcend our origins in national traditions.

I agree with Severi about language imperialism, but I don't see us reducing Digital Anthropology either to issues of storage or even communication. In the introduction to Digital Anthropology we use dialectical theory to argue that the digital is actually a simultaneous expansion of universality and particularly, analogous with, say, money. This is why I insist that we have two debates here, one about Open Access and another about Digital Anthropology.

In conclusion, I am delighted to have garnered these lively responses. Robust argument is our academic lifeblood. I suspect in terms of the wider aims we are all on the same side here, and collectively sense that this is the time for action. Our discussion coincides with extraordinary developments such as support from Harvard and the Wellcome Institute. I am inclined to be radical, to consider transforming, not just complementing, most current publishing. The main debates are around journals, but my paper also addressed books. We should be learning from best practice (e.g., Adema 2010), from scholarly work on the publishing industry (e.g., Thompson 2005, 2010) and the wider context of academic needs and practices (Harley et al. 2010).

To take Macintyre's issue of feasibility, the universities will save a fortune if they refuse subscription to overly expensive publishers. We should collectively argue that some of this money allows the universities to take back the mantle they once held of academic publishing, including the costs of managing, editing, reviewing, and marketing while retaining professional standards. The reason for optimism is because the costs this would impose on universities are so much less than the money they can thereby save. This is the open door we should now push at. In anthropology we should discuss with the established journals and key presses how best to shift all the discipline's journals to Open Access and its implications for revenue. Several experienced journal editors made comments on my paper.

I am grateful to $H A U$ for facilitating a discussion of issues that have a real bearing on our lives and those of our students. I hope it is clear that my aim is not to be right in principle, but to support whatever in practice moves us towards this larger collective goal, gleaning helpful and critical points from the wide experience of these interlocutors and the differences in regional practice.

\section{References}

Adema, Janneke. 2010. "Overview of Open Access Models for eBooks in the Humanities and Social Sciences." Open Access Publishing in European Networks. http://bpfe.eclap.eu/eclap/axmedis/4/4b3/00000-4b3ca034-a3a54be4-aaaa-cea1 1bcb7bbc/2/AXMEDIS7675.pdf. 
Chakrabarty, Dipesh. (2000) 2007. Provincializing Europe: Postcolonial Thought and Historical Difference. New Edition with a new preface from the author. Princeton, NJ: Princeton University Press.

Cherny, Lynn, and Elizabeth Reba Weise. 1996. Wired women: Gender and new realities in cyberspace. Seattle, WA: Seal Press.

Cohen, Noam. 2011. "Define gender gap? Look up Wikipedia’s contributor list.” New York Times, January 30. http://www.nytimes.com/2011/01/31 /business/media/ 31link.html?_r=1.

Coleman, Gabriella. 2004. "The political agnosticism of free and open source software and the inadvertent politics of contrast." Anthropological Quarterly 77 (3): $507-519$.

- 2009. "Code is speech: Legal tinkering, expertise, and protest among free and open source software developers.” Cultural Anthropology 24 (3): 420-54.

- 2010. "The hacker conference: A ritual condensation and celebration of a lifeworld.” Anthropological Quarterly 83 (1): 47-72.

da Col, Giovanni, and David Graeber. 2011. "Foreword: The return of ethnographic theory." HAU:Journal of Ethnographic Theory 1 (1): vi-xxxv.

Dibbell, Julian. 1998. My tiny life: Crime and passion in a virtual world. New York: Holt.

Faubion, James D., and George E. Marcus. 2009. Fieldwork is not what it used to be: Learning anthropology's method in a time of transition. Ithaca, NY: Cornell University Press.

Fortun, Kim. 2011. "Experimenting with the asthma files 3.0." Paper read at the annual American Anthropological Association meetings, Montreal, Canada. November 20.

Goody, Jack. 1977. The domestication of the savage mind. Cambridge: Cambridge University Press.

Gregory, Chris A. 1997. Savage money: The anthropology and politics of commodity exchange. Amsterdam: Harwood Academic Publishers.

Haraway, Donna. 1985. "A manifesto for cyborgs-Science, technology, and socialist feminism in the 1980s." Socialist Review 80: 65-107

Harley, Diane, et al. 2010. Assessing the future landscape of scholarly communication: An exploration of faculty values and needs in seven disciplines. Berkeley, CA: Center for Studies in Higher Education, University of California, Berkeley.

Hart, Keith. 2000. The memory bank: Money in an unequal world. London: Profile Books.

Horst, Heather, and Daniel Miller, eds. 2012. Digital Anthropology. Oxford: Berg Publishers.

Karanović, Jelena. 2008. "Sharing publics: Democracy, cooperation, and free software advocacy in France.” PhD dissertation. New York University. 
- 2012. "Free Software and the Politics of Sharing." In Digital Anthropology, edited by Heather Horst and Daniel Miller, 185-202. Oxford: Berg Publishers

Kelty, Christopher M. 2008. Two bits: The cultural significance of free software. Durham, NC: Duke University Press.

Kendall, Lori. 2002. Hanging out in the virtual pub: Masculinities and relationships online. Berkeley, CA: University of California Press.

Leach, J., D. Nafus, and B. Krieger. 2009. "Freedom imagined: Morality and aesthetics in open source software design." Ethnos 74 (1): 51-71.

Lin, Thomas. 2012. "Mathematicians Organize Boycott of a Publisher." New York Times, February 13. http://www.nytimes.com/2012/02/14/science/researchersboycott-elsevier-journal-publisher.html.

Madianou, Mirca, and Daniel Miller. 2012. Migration and new media: Transnational families and Polymedia. London: Routledge.

Marcus, George E., and Michael M. J. Fischer. 1986. Anthropology as cultural critique: An experimental moment in the human sciences. Chicago, IL: University of Chicago Press.

McSherry, Corynne. 2001. Who owns academic work? Battling for control of intellectual property. Cambridge, MA: Harvard University Press.

Miller, Daniel. 1987. Material culture and mass consumption. Oxford: Blackwell.

—. 2005. "Can't publish and be damned." Anthropology Matters 7 (2): 1-8.

Miller, Daniel, and Heather Horst. 2012. "The digital and the human.” In Digital Anthropology, edited by Heather Horst and Daniel Miller, 3-35. Oxford: Berg Publishers.

Miller, Daniel, and Don Slater. 2000. The Internet: An ethnographic approach. Oxford: Berg Publishers.

Pertierra, Raul, Eduardo. Ugarte, Alicia. Pingol, Joel. Hernandez, and Nikos. Dacanay. 2002. TXT-ING selves: Cellphones and Philippine modernity. Manila: De La Salle University Press.

Severi, Carlo. 2007. Le principe de la chimère. Une anthropologie de la mémoire. Paris: Presses de l'École Normale Supérieure (Rue d'Ulm) et Musée du Quai Branly.

Simmel, Georg. 1978. The philosophy of money. London: Routledge.

Thompson, John. 2005. Books in the digital age: The transformation of academic and higher education publishing in Britain and the United States. Cambridge: Polity Press.

- 2010. Merchants of culture: The publishing business in the twenty-first century. Cambridge: Polity Press. 
Thompson. Matt. 2012. "Alright, how about a digital anthropology interest group?" Savage Minds (blog), December 2. http://savageminds.org/2012/02/21/alrighthow-about-a-digital-anthropology-interest-group/.

Van Heekeren, Deborah. 2012. The shark warrior of Alewai: A phenomenology of Melanesian identity. London: Sean Kingston Press.

van Veggel, Rob. 2009. The potters and pottery of Miravet: Production, marketing and consumption of pottery in Catalonia. London: Sean Kingston Press.

\section{Le Libre Accès, la recherche, et l'anthropologie numérique}

Résumé : Cet article présente trois arguments. Le premier préconise le libre accès aux ouvrages et aux revues anthropologiques, et critique la manière par laquelle a été cédé le contrôle de leur diffusion à des finalités commerciales qui ont pris le pas sur les critères académiques qui auraient dû prédominer. Le deuxième argument affirme que la meilleure façon d'accomplir ce but est de procéder de manière conservatrice en ce qui concerne les processus d'évaluation, de sélection, et les canons de la recherche. En troisième, l'article examine l'émergence de l'Anthropologie Numérique, suggérant son rôle primordial dans la conceptualisation de l'anthropologie et de son avenir, et en proposant une définition. Ceci doit être distingué des thèmes du libre accès et de l'évaluation scientifique. Dix commentaires critiques utiles suivent l'article. Dans la discussion finale, j’y réponds en montrant la manière dont ils peuvent être pris en compte dans le contexte d'un changement vers le libre accès, qui promeuve en même temps le concept d'Anthropologie Numérique.

Daniel MiLLER teaches material culture at the Department of Anthropology, University College London where he also recently established a course in Digital Anthropology. He is currently leading an ERC project on the impact of social networking sites on seven countries. Recent books include Global Denim (Berg 2011, edited with S. Woodward), Tales from Facebook (Polity 2011), Migration and New Media (Routledge 2012, with M. Madianou), Blue Jeans (California 2012, with S. Woodward), Consumption and its Consequences (Polity 2012) and Digital Anthropology (Berg 2012, edited with H. Horst). 